\title{
IUCN captive management guidelines support ex situ conservation of the Bengal florican Houbaropsis bengalensis blandini
}

\author{
Simon P. Mahood, Chamnan Hong, Michael Meyerhoff, Pau P. Ferrando \\ Phearun Sum, Virak Son, Pengann Ouch and Stephen T. Garnett
}

\begin{abstract}
Ex situ conservation of species is risky and expensive, but it can prevent extinction when in situ conservation fails. We used the IUCN Guidelines on the Use of Ex Situ Management for Species Conservation to evaluate whether to begin ex situ conservation for the South-east Asian subspecies of Bengal florican Houbaropsis bengalensis blandini, which is predicted to be extinct in the wild within 5 years. To inform our decision, we developed a decision tree, and used a demographic model to evaluate the probability of establishing a captive population under a range of husbandry scenarios and egg harvest regimes, and compared this with the probability of the wild population persisting. The model showed that if ex situ conservation draws on international best practice in bustard husbandry there is a high probability of establishing a captive population, but the wild population is unlikely to persist. We identified and evaluated the practical risks associated with ex situ conservation, and documented our plans to mitigate them. Modelling shows that it is unlikely that birds could be released within 20-30 years, by which time genetic, morphological and behavioural changes in the captive population, combined with habitat loss and extinction of the wild population, make it unlikely that Bengal florican could be released into a situation approximating their current wild state. We considered the philosophical and practical implications through a decision tree so that our decision to begin ex situ management is not held back by our preconceived notions of what it means to be wild.
\end{abstract}

SIMON P. MAHOOD* (Corresponding author, (D) orcid.org/0000-0001-9459-1064) and STEPHEN T. GARNETT (iD orcid.org/0000-0002-0724-7060) Research Institute for the Environment and Livelihoods, Charles Darwin University, Ellengowan Drive, Casuarina, Northern Territory 0810, Australia

E-mail simonpeter.mahood@cdu.edu.au

Chamnan Hong* and VIrak Son ${ }^{*}$ Department of Freshwater Wetland Conservation, Ministry of Environment, Phnom Penh, Cambodia

Michael Meyerhoff and Pau P. Ferrando Angkor Centre for Conservation of Biodiversity, Kbal Spean, Cambodia

Phearun Sum Wildlife Conservation Society, Phnom Penh, Cambodia

Pengann Ouch Department of Wildlife and Biodiversity, Forestry Administration, Ministry of Agriculture, Forestry and Fisheries, Phnom Penh, Cambodia

${ }^{*}$ Also at: Wildlife Conservation Society, Phnom Penh, Cambodia

Received 20 May 2019. Revision requested 9 September 2019.

Accepted 21 December 2019. First published online 26 March 2021.
Keywords Bengal florican, bustard, captive management, decision tree, demographic modelling, ex situ conservation, extinction, IUCN guidelines

Supplementary material for this article is available at doi.org/10.1017/So030605319001510

\section{Introduction}

- $x$ situ management is increasingly used to prevent

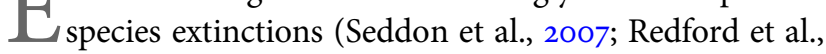
2011), with 34 animals and 35 plants categorized as Extinct in the Wild and thus relying entirely on persistence of populations in captivity (IUCN, 2019). Successful case studies include the California condor Gymnogyps californianus in the Americas (Snyder \& Snyder, 2000) and crested ibis Nipponia nippon in Asia (Xi et al., 2002). The hope that these examples engender, coupled with the dire situation facing an increasing number of species in the wild (Butchart et al., 2010), manifests in recommendations for captive breeding in the IUCN Red List accounts of 2,199 threatened or Near Threatened species (IUCN Conservation Planning Specialist Group, 2019). However, zoos can conserve only a small proportion of threatened species (Balmford et al., 1996), and the familiarity of successful case studies masks the fact that ex situ management is difficult, risky, time-consuming and financially costly, and can increase the risk of extinction for wild populations by removing individuals from the wild to create founder populations (Snyder et al., 1996). A comprehensive global evaluation of conservation reintroduction, reinforcement or replacement case studies found that $72 \%$ of those with a known outcome succeeded and $28 \%$ failed; not eliminating the cause of decline was the greatest cause of failure (Bubac et al., 2019). Faced with data that indicate a rapidly declining population, conservation managers must make a timely, informed decision regarding whether or not to proceed with ex situ management (McGowan et al., 2017). A failure to act quickly on available evidence of species declines can lead to extinctions (Martin et al., 2012), but making the wrong decision can also increase the risk of extinction (Snyder et al., 1996).

Management of species occurs along a continuum of states ranging from free-ranging self-sustaining wild populations to species that exist only in captivity (Redford et al., 
2011). Lines between states are increasingly blurred as a result of the increase in ex situ management (Redford et al., 2012) and the variety of ex situ management regimes from small cages to extensive semi-natural environments. We follow the intuitive definition in IUCN/SSC (2014), which defines ex situ as conditions under which 'the individuals are maintained in artificial conditions under different selection pressures than those in natural conditions in a natural habitat'. Duration of time in ex situ conditions can vary from short, for example the temporary removal of a population during predator control, to indefinite, for species for which there is no hope of reintroduction in the foreseeable future. Ex situ management has a range of purposes, including conservation (through establishing insurance populations, breeding for reintroduction, head-starting and research), education and restocking for sport (Fischer \& Lindenmayer, 2000; Harding et al., 2016). Here we consider only captive breeding for preventing extinctions of species (i.e. the complete loss of all individuals of the species), for which we use the term ex situ conservation. The ultimate goal of ex situ conservation in this context is the reinforcement or reintroduction of wild populations, which distinguishes it from capture solely to establish captive populations for display, education, farming or keeping as pets. For this reason, individuals maintained and bred for ex situ conservation should be theoretically capable of producing offspring that can survive in the wild. Ideally, where possible, a parallel programme of in situ conservation should ensure that populations are maintained in the wild. However, ex situ conservation can inadvertently compromise source populations by harvesting too many individuals from free-ranging populations (increasing rates of decline), or distracting decision makers such as governments and funders to the detriment of in situ conservation (Snyder et al., 1996). The IUCN guidelines suggest that success of in situ conservation should not be unduly jeopardized by ex situ conservation (IUCN/SSC, 2013, 2014) unless conditions in the wild are so hostile that the ex situ conservation plan requires that the entire wild population is taken into captivity (McCleery et al., 2014).

Ex situ conservation can buy time for conservation managers to address causes of decline by eliminating introduced predators, restoring habitat or enacting legislative changes that create conditions for species to survive in a wild state (Andrew et al., 2018), but it must begin when there are sufficient wild individuals to establish a captive population. Species whose extinction might otherwise have been prevented, such as a number of reptiles and a bat (Christmas Island pipistrelle Pipistrellus murrayi) endemic to Christmas Island, and the po'ouli Melamprosops phaeosoma, were lost because plans for ex situ conservation were not enacted until too few individuals remained (VanderWerf et al., 2006; Martin et al., 2012; Andrew et al., 2018). Although most risks emanating from ex situ conservation can be mitigated, this is costly and time-consuming and none can be prevented entirely. However, avoidance of decisions about ex situ conservation because of perceptions of risk, fear of failure and fear of being perceived to have made the wrong decision is itself a decision to do nothing (Brook et al., 2014) and can lead to extinctions (Woinarski et al., 2017).

IUCN has developed guidelines to help conservation managers determine how and when ex situ management should be used in conservation (IUCN/SSC, 2014). The guidelines provide a logical five-step decision-making process that finishes with a call to make a decision that is informed by the information gathered in the preceding four steps and 'weighing the potential conservation benefit to the species against the likelihood of success and overall costs and risks of not only the proposed ex situ programme, but also alternative conservation actions or inaction' (IUCN/ SSC, 2014; McGowan et al., 2017). Step 1 is a review of the status of the species, in Step 2 the role(s) that ex situ management could play in the conservation of the species are defined, Step 3 is an evaluation of the precise nature of the desired ex situ population to meet identified role(s), and in Step 4 resources, expertise, feasibility and risks are appraised (McGowan et al., 2017). There is no method proposed for the critical fifth step, which is to make the decision on whether to initiate captive breeding. Because captive breeding for conservation can be risky and controversial, decision-making should be conducted using a method that enables wide participation in the process so that practitioners have ownership of the results rather than feeling disempowered by top-down systems of management (Black et al., 2011). Hidden value judgments can be revealed and managed by following a transparent process that documents why and how decisions were made, with uncertainty acknowledged and quantified where possible so that it can be incorporated into the decision-making process (Game et al., 2013). However, without the aid of tools, people struggle to quantify risk in decision-making processes (Redford \& Taber, 200o). The tool used most commonly for structured decision analysis in conservation is the decision tree (Maguire, 1986; Gregory et al., 2012; Panfylova et al., 2019). Decision trees have been used to choose between ex situ conservation and other options to varying degrees of success, but when a species is under imminent threat of extinction in the wild the chance of success for any conservation plan is low (Regan et al., 2005).

Here, we apply the IUCN Guidelines (IUCN/SSC, 2014) to the South-east Asian subspecies of Bengal florican Houbaropsis bengalensis blandini, a Critically Endangered bustard now restricted to Cambodia (BirdLife International, 2018b). Although IUCN/SSC (2014) calls for dissemination of information regarding use of the guidelines, we have not found any peer reviewed articles that explicitly document their use. Since the mid 2ooos (the date of the first reliable population data), the Bengal florican has experienced a decline of $>10 \%$ per annum (Gray et al., 2009; Packman et al., 
2013b; Mahood et al., 2019) as a result of habitat loss, agricultural intensification, hunting, and predation by freeranging domestic dogs (Packman et al., 2013a; Ibbett et al., 2019). In 2018 the population was estimated to be 138 (95\% CI 119-156) birds at four sites where display activity still occurred, and one site (Koup Preah Buong Trea) where a few additional birds remain (Mahood et al., 2019). Intensive in situ conservation efforts stabilized population trends at one site, Stoung-Chikreang Bengal Florican Conservation Area (Mahood et al., 2019), but that population is now threatened by a newly-constructed power line that could lead to local extinction (Mahood et al., 2016). Given the dire situation facing the species there have been calls from within Cambodia to consider captive management to prevent its global extinction (M. Meyerhoff, pers. comm., 2018). Mindful of the need to make a timely decision on whether to proceed with captive management, but aware of the potential risks of making the wrong decision, we use the IUCN Guidelines to make a decision about ex situ conservation of the Bengal florican. Instructions for using the guidelines are available (McGowan et al., 2017), but not tools for each step or a worked example. We developed simple tables to evaluate the issues for consideration under Steps 3 and 4 , and a decision tree for Steps 2 and 5 . We use a demographic model developed by Dolman et al. (2015) to inform Step 3 and explore the probability of success of ex situ conservation (Addison et al., 2013). We show how these tools enabled us to make a decision about ex situ conservation of the Bengal florican and hope that the decision tree will assist other conservation managers facing similar predicaments.

\section{Methods}

\section{Development of tools}

We first conducted a review of the status of the Bengal florican (Mahood et al., 2019), following Step 1 of the guidelines (IUCN/SSC, 2014). We created a decision tree that combined Step 2 (identification of the potential role of ex situ conservation in the conservation of the species) with the part of Step 4 that evaluates risk to the wild population from ex situ conservation (Fig. 1). We created a table to evaluate the practical considerations associated with ex situ conservation of the species (Table 1: Step 3), and a similar table to evaluate practical risks (Table 2: Step 4). The practical risks were separated from risks to the wild population because they can be mitigated, unlike biological risks for which mitigation is often difficult or impossible.

\section{Demographic modelling}

To inform our evaluation of practical and biological risks to the wild and captive populations (Step 3), and evaluate whether ex situ management would increase the probability of persistence, we used a publicly available demographic model developed for evaluating the efficacy of captive breeding for the great Indian bustard Ardeotis nigriceps (Dolman et al., 2015). We retained the same parameters as Dolman et al. (2015), who used data from a range of medium and large-sized bustard species, except where data existed for Bengal florican or the more similarly-sized little bustard Tetrax tetrax, or where variation was expected based on the smaller body size of the Bengal florican (Supplementary Tables 1 \& 2). As these parameters include data from a number of bustard species that are larger and possibly slower to mature than the Bengal florican, they are likely to yield a conservative estimate of the chance of persistence (see Dolman et al., 2015, for detailed methodology; only key points are summarized here). Where we differ most from Dolman et al. (2015) is in the nature of the situation with which we compare captive breeding. They compared the effect on the wild population of either pursuing a programme of captive breeding and subsequent release, or improving the efficacy of in situ conservation in the absence of captive breeding. In our case, with or without ex situ conservation the wild population continues to decline at an accelerated rate, even though since 2005 everything possible (within the constraints of relevant socio-economic and political factors) has been attempted to maintain it.

The model allowed us to evaluate the chance of persistence of a captive population under various strategies for collecting eggs from the wild, and the probability that individuals could be released within 50 years. We did not consider capture of adults from the wild because captive facilities that breed bustards advised against it. We did not use our model to evaluate the probability of persistence of the wild population because we had insufficient data to parameterize the model, but the current trajectory, based on data from 12 years of population monitoring, suggests that the Bengal florican will be functionally extinct by 2023 (Mahood et al., 2019). The captive breeding model assumes that we can collect a maximum of five or 10 eggs in the first year (the mean number of eggs found annually during 20142018 is 7.4; Wildlife Conservation Society, unpubl. data), but that this will decline by two eggs per year for 5 years as the wild population declines. The release model assumes that all released birds are $<_{1}$ year of age, to minimize behavioural adaptation to captivity (Inchausti \& Bretagnolle, 2005). Following Dolman et al. (2015), releases do not occur until the captive population has reached 20 mature females so as not to jeopardize the persistence of the captive population (IUCN/SSC, 2013); we set the minimum group size of released birds to five because a minimum of four males plus one female is required for a Bengal florican exploded lek to function (Gray et al., 2009). For captive management models, we considered four scenarios of performance quality to account for variation in demographic performance of 


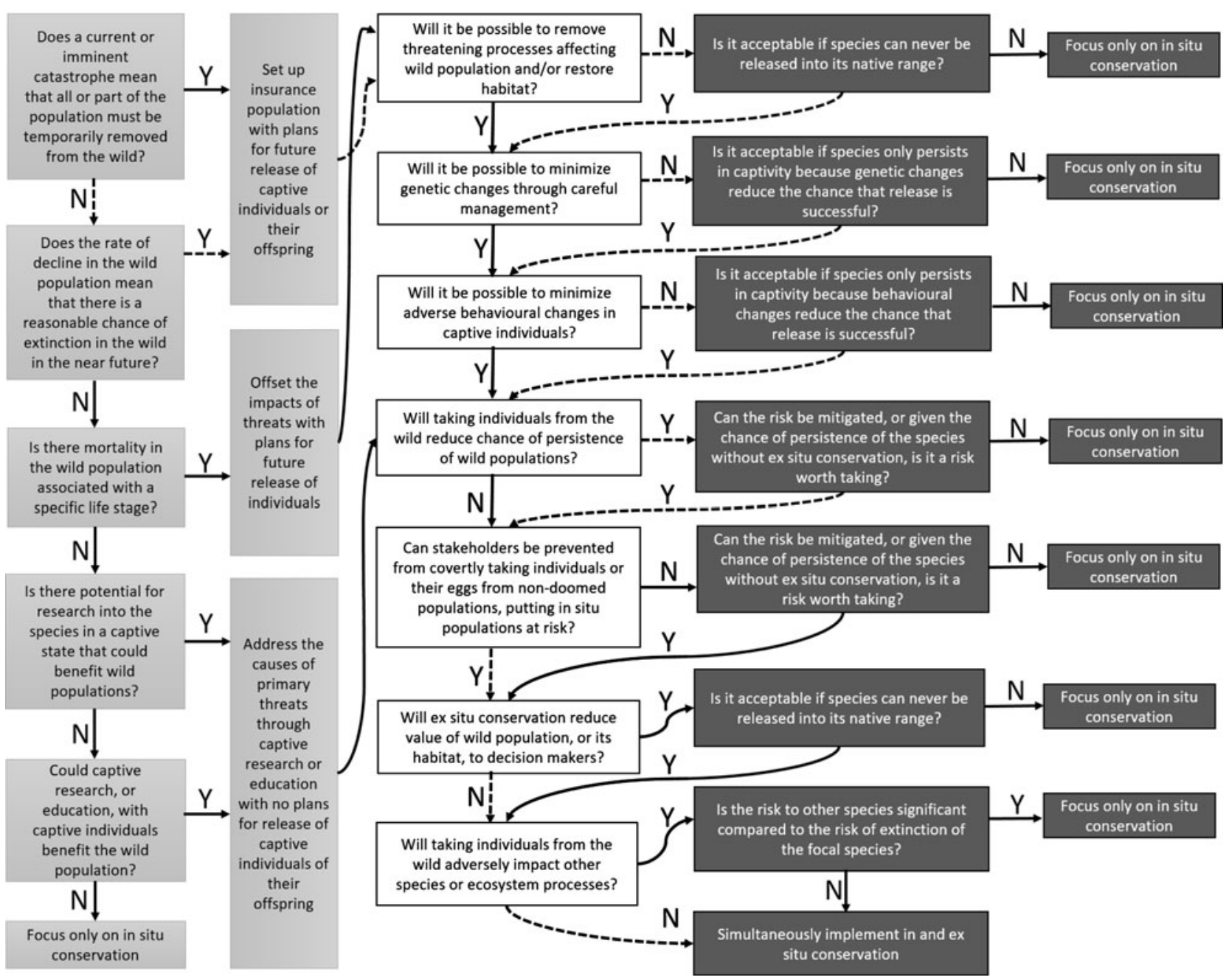

FIG. 1 Steps 2 (pale grey boxes), 4 (white boxes) and 5 (dark grey boxes): decision tree to help conservation managers determine the kind of ex situ management required, and consider biological risks associated with ex situ management. Dashed arrows indicate the consensus of the stakeholder meeting for the Bengal floricon Houbaropsis bengalensis blandini.

captive management: full range, below average, above average and best possible, and accounted for the impacts of stochastic events (for parameters, see Supplementary Table 1; for methodological details, see Dolman et al., 2015). Outcomes of the captive breeding programme were assessed against the proportion of 1,000 model runs persisting by year 50, whether they provided surplus individuals for release (without compromising the maintenance of a captive population of $>20$ mature females), and numbers of breeding age birds established in the wild, following Dolman et al. (2015).

\section{Assessment process}

At a meeting held in April 2019 in Phnom Penh, Cambodia, all relevant stakeholders took part in the application of the IUCN guidelines for assessment of the potential role of ex situ management for the Bengal florican (all participants are co-authors here), including representatives from the relevant government ministries (Ministry of Environment and the Forestry Administration of Ministry of Agriculture, Forestry and Fisheries), the only NGO working on in situ conservation of the Bengal florican (Wildlife Conservation Society), and the captive facility that had expressed interest in ex situ management of the species (Angkor Centre for the Conservation of Biodiversity). The scope of the meeting and agenda were agreed in advance. Presentations were given to summarize the results of the status review (Step 1) and the demographic modelling described here. Participants worked through the first part of the decision tree to identify the role that ex situ management could play in conservation of the species (Step 2). Presentations were given on case studies of ex situ conservation successes and failures, facilities at Angkor Centre for the Conservation of Biodiversity, and ex situ conservation of bustards worldwide. Tables of practical considerations (Step 3: Table 1) and practical and 
TABLE 1 Step 3: evaluation of biological and practical considerations associated with ex situ conservation of the Bengal florican Houbaropsis bengalensis blandini.

\begin{tabular}{|c|c|c|}
\hline Considerations & Desired state $^{1}$ & Likely state $^{1}$ \\
\hline $\begin{array}{l}\text { Required number of } \\
\text { founders }\end{array}$ & Harvest 5-10 eggs per year for at least 5 years & $\begin{array}{l}\text { Harvest as many eggs as possible from doomed popula- } \\
\text { tions; harvest eggs only from July onwards from popu- } \\
\text { lations with a hope of persistence }\end{array}$ \\
\hline $\begin{array}{l}\text { Number of individuals to } \\
\text { be maintained ex situ }\end{array}$ & $>20$ breeding age females, more if possible & $\begin{array}{l}58-85 \% \text { chance that this can be achieved over } 50 \text { years } \\
\text { under above-average scenario, depending on number of } \\
\text { eggs harvested annually }\end{array}$ \\
\hline $\begin{array}{l}\text { Likely duration of ex situ } \\
\text { programme }\end{array}$ & $\begin{array}{l}>50 \text { years: under above-average scenario } \\
\text { minimum of } 30 \text { years needed until ex situ } \\
\text { population is established }\end{array}$ & $\begin{array}{l}58 \% \text { chance that this can be achieved under above- } \\
\text { average scenario if } 5 \text { eggs harvested per year }\end{array}$ \\
\hline $\begin{array}{l}\text { Relative risk of behavioural } \\
\text { adaptation to ex situ } \\
\text { conditions }\end{array}$ & $\begin{array}{l}\text { Moderate, managed through handling protocols } \\
\text { \& cage design }\end{array}$ & $\begin{array}{l}\text { High; behavioural adaptation to captivity is initially de- } \\
\text { sirable to minimize adult mortality; birds bred for release } \\
\text { will be managed differently, to minimize adaptation }\end{array}$ \\
\hline Inbreeding & $\begin{array}{l}\text { Moderate, managed through maximizing the } \\
\text { number of founders, genetic testing of all indivi- } \\
\text { duals \& planned mating through use of a studbook }\end{array}$ & Moderate, managed as in the desired state \\
\hline Disease management & $\begin{array}{l}\text { Single species facility with stringent quarantine } \\
\text { procedures }\end{array}$ & $\begin{array}{l}\text { Captive facility only keeps species that originate from } \\
\text { Cambodia, standard quarantine \& disease risk reduction } \\
\text { procedures are in place }\end{array}$ \\
\hline $\begin{array}{l}\text { Plans for a release/ } \\
\text { reintroduction }\end{array}$ & $\begin{array}{l}\text { Only at such a time that it does not jeopardize } \\
\text { the captive population }\end{array}$ & $\begin{array}{l}\text { Unlikely to be possible before } 2050 \text {, for which it is } \\
\text { impossible to predict suitability of wild conditions }\end{array}$ \\
\hline Egg harvest method & $\begin{array}{l}\text { Close supervision of search teams by ACCB \& } \\
\text { WCS staff }\end{array}$ & $\begin{array}{l}\text { Local people asked to report nests to WCS, eggs harvested } \\
\text { from nests by ACCB staff }\end{array}$ \\
\hline $\begin{array}{l}\text { Geographical location } \\
\text { of facility }\end{array}$ & $\begin{array}{l}\text { Proximate to native range (cannot locate inside } \\
\text { breeding range because of seasonal flooding) }\end{array}$ & Proximate to native range \\
\hline Nature of facility & Single species & $\begin{array}{l}\text { Multi-species, located at ACCB, an animal rescue, } \\
\text { rehabilitation \& captive breeding centre managed } \\
\text { by Allwetterzoo Münster, Germany }\end{array}$ \\
\hline Design of facility & $\begin{array}{l}\text { Large enclosures with ample space for flying } \\
\text { replicate wild conditions }\end{array}$ & $\begin{array}{l}\text { Small enclosures, breeding \& non-breeding birds kept } \\
\text { separately, birds not encouraged to fly for fear of injury; } \\
\text { priority given to minimizing mortality }\end{array}$ \\
\hline Equipment & State of the art & $\begin{array}{l}\text { All necessary equipment, \& backup equipment, has been } \\
\text { purchased \& is ready to use }\end{array}$ \\
\hline Staff numbers \& skills & Dedicated Bengal florican staff team & $\begin{array}{l}\text { Dedicated bird keeper \& veterinarian, florican staff will } \\
\text { not work on husbandry of other bird species, to minimize } \\
\text { disease risk }\end{array}$ \\
\hline Marking of individuals & $\begin{array}{l}\text { Colour rings \& microchips on all birds, database } \\
\text { (Species360, 2020) \& stud book kept up to date }\end{array}$ & As desired state \\
\hline Behavioural management & Birds handled as infrequently as possible & $\begin{array}{l}\text { Birds for captive breeding will be habituated as chicks, } \\
\text { to facilitate easy handling \& reduce mortality }\end{array}$ \\
\hline Level of public display & Birds not on public display & $\begin{array}{l}\text { Birds not on public display, all visitors to the facility will } \\
\text { be escorted by staff }\end{array}$ \\
\hline
\end{tabular}

${ }^{1}$ ACCB, Angkor Centre for Conservation of Biodiversity; WCS, Wildlife Conservation Society.

logistical risks (Step 4: Table 2) were populated in advance with issues for consideration, using IUCN/SSC (2014). Participants were also invited to identify additional issues, which were then added to the tables. The whole group assessed the biological risks associated with ex situ management, using the decision tree (Steps 4 and 5) for the population as a whole, and for each of the four remaining subpopulations. Results were summarized by the facilitator. A basic plan for ex situ management was developed based on the outcome and outputs of the meeting (Step 5: Table 3).

\section{Results}

Using the decision tree, the group decided to proceed with ex situ management of the Bengal florican, despite the risks, because of rapid, and potentially accelerating, declines in the wild population, the likelihood that threats could not be controlled in the wild before the taxon was rendered extinct, and the relatively high probability of establishing a captive population (Fig. 1). The demographic modelling indicated there is a $58 \%$ probability of a captive population persisting for 50 years under the above-average scenario of egg harvest 
TABLE 2 Step 4: evaluation of logistical and practical risks associated with ex situ conservation of the Bengal florican.

\begin{tabular}{|c|c|c|c|}
\hline Risk area & Present situation ${ }^{1}$ & Score & How risk is mitigated ${ }^{1}$ \\
\hline Harvest of eggs from the wild & $\begin{array}{l}\text { Community members who find nests may } \\
\text { misunderstand \& take eggs to their homes } \\
\text { before reporting them }\end{array}$ & High & $\begin{array}{l}\text { Clear protocol developed, WCS community } \\
\text { staff communicate clearly \& frequently with } \\
\text { local people \& ACCB }\end{array}$ \\
\hline Transportation of eggs & $\begin{array}{l}\text { One vehicle with portable incubator run } \\
\text { from car engine }\end{array}$ & Low & Vehicle always kept ready for use \\
\hline Equipment & $\begin{array}{l}\text { One incubator \& foster chickens available, } \\
\text { no other specific equipment needed }\end{array}$ & Low & Keep equipment well maintained \\
\hline Facilities \& infrastructure & $\begin{array}{l}\text { Temporary enclosure constructed with } \\
\text { four compartments }\end{array}$ & Medium & $\begin{array}{l}\text { Facilities adequate for short term, in medium } \\
\text { term upgrade \& expand existing facilities }\end{array}$ \\
\hline Staff numbers \& skills & $\begin{array}{l}\text { Sufficient staff with experience of keeping } \\
\text { birds, experience of care for one adult } \\
\text { Bengal florican }\end{array}$ & Low & Maintain staff at current levels \\
\hline Husbandry techniques & $\begin{array}{l}\text { Species has never been kept in captivity } \\
\text { for more than } 3 \text { months }\end{array}$ & Medium & $\begin{array}{l}\text { Ongoing technical support is available from } \\
\text { staff at other facilities with significant } \\
\text { experience in husbandry of bustards }\end{array}$ \\
\hline Food availability & $\begin{array}{l}\text { Insects widely sold for human consump- } \\
\text { tion in Cambodia, cricket breeding farm } \\
\text { in Phnom Penh }\end{array}$ & Medium & $\begin{array}{l}\text { Purchase crickets from cricket farm, in } \\
\text { medium term develop on-site cricket or } \\
\text { insect breeding farm }\end{array}$ \\
\hline $\begin{array}{l}\text { Spread of disease to wild } \\
\text { population }\end{array}$ & Captive facility is outside the species range & Low & None required \\
\hline $\begin{array}{l}\text { Spread of disease within } \\
\text { captive facility }\end{array}$ & $\begin{array}{l}\text { Costs prohibit building \& staffing a } \\
\text { single-species facility, rescued birds of } \\
\text { other species are a disease risk at ACCB }\end{array}$ & Medium & $\begin{array}{l}\text { Follow standard quarantine protocols, restrict } \\
\text { staff movements between cages of Bengal } \\
\text { florican \& other species }\end{array}$ \\
\hline $\begin{array}{l}\text { Catastrophes (e.g. fire \& smoke } \\
\text { inhalation, wind, war) }\end{array}$ & $\begin{array}{l}\text { Facility is located in a tropical climate in } \\
\text { an area with frequent fires }\end{array}$ & Medium & $\begin{array}{l}\text { Fire break constructed around facility; } \\
\text { fire-fighting service unlikely to travel to } \\
\text { facility but there is basic fire-fighting } \\
\text { equipment on site }\end{array}$ \\
\hline Theft of birds & Low value species & Low & Monitor situation \\
\hline Revenge attack on facility & $\begin{array}{l}\text { No reason to suspect an attack is likely, } \\
\text { but possible within cultural context }\end{array}$ & Low & Monitor situation \\
\hline Financial resources & Sufficient for small-scale start up & Medium & $\begin{array}{l}\text { Fundraising ongoing, targeting sources that } \\
\text { would not fund in situ conservation; project } \\
\text { will be promoted widely }\end{array}$ \\
\hline Clarity of taxonomy & $\begin{array}{l}\text { All birds in source areas are the same } \\
\text { taxon }\end{array}$ & Low & $\begin{array}{l}\text { Birds will not be obtained from outside } \\
\text { Cambodia }\end{array}$ \\
\hline $\begin{array}{l}\text { Legal requirements } \\
\text { (e.g. permits) }\end{array}$ & Permits do not exist for facility & High & $\begin{array}{l}\text { Government staff in the recovery team will } \\
\text { assist with obtaining permits to harvest eggs } \\
\text { from wild birds \& transport them to the } \\
\text { facility }\end{array}$ \\
\hline $\begin{array}{l}\text { Lack of collaboration between } \\
\text { government \& non- } \\
\text { government stakeholders }\end{array}$ & $\begin{array}{l}\text { Bengal Florican Recovery Team has } \\
\text { government \& non-government } \\
\text { members }\end{array}$ & Low & Add stakeholders to team as needed \\
\hline Health \& safety of people & $\begin{array}{l}\text { Species does not pose a direct risk to } \\
\text { people }\end{array}$ & Low & $\begin{array}{l}\text { All adults \& chicks will be tested for zoonotic } \\
\text { diseases }\end{array}$ \\
\hline Political conflicts of interest & $\begin{array}{l}\text { Misconception that foreigners export } \\
\text { Bengal floricans or breed them for food }\end{array}$ & Medium & $\begin{array}{l}\text { Local government \& communities will } \\
\text { be consulted \& informed about ex situ } \\
\text { conservation of Bengal florican }\end{array}$ \\
\hline Cultural conflicts of interest & None & Low & None required \\
\hline
\end{tabular}

${ }^{1}$ ACCB, Angkor Centre for Conservation of Biodiversity; WCS, Wildlife Conservation Society.

rates of five per year for 5 years; this rises to $85 \%$ if harvest rates are 10 per year (Fig. 2). For the best possible scenario, probability of captive programme persistence is $89 \%$ even if egg harvest rates are only five per year for 5 years. The group considered that it was likely that harvest rates would be 5-10 eggs per year, but given the rate of decline of the wild population it was unlikely that harvest could continue beyond 5 years.

Under the below-average scenario, the captive population is never successfully established, and under the full-range scenario there is only a $19 \%$ chance of persistence of a captive population within 50 years (at egg harvest rates of five 
TABLE 3 Step 5: plan for harvest of eggs of the Bengal florican.

\begin{tabular}{|c|c|c|c|c|c|}
\hline Year & Stoung-Chikreang & Baray & Sankor & Bakan & $\begin{array}{l}\text { Koup Preah Buong } \\
\text { Trea }\end{array}$ \\
\hline 2019 & $\begin{array}{l}\text { Only collect eggs from } \\
\text { July onwards; monitor } \\
\text { powerline mortality }\end{array}$ & $\begin{array}{l}\text { Only collect eggs from } \\
\text { July onwards; monitor } \\
\text { field situation }\end{array}$ & $\begin{array}{l}\text { Collect all eggs } \\
\text { immediately; monitor } \\
\text { field situation }\end{array}$ & $\begin{array}{l}\text { Monitor field } \\
\text { situation }\end{array}$ & $\begin{array}{l}\text { Collect all eggs } \\
\text { immediately; monitor } \\
\text { field situation }\end{array}$ \\
\hline 2020 & $\begin{array}{l}\text { Only collect eggs from } \\
\text { July onwards; monitor } \\
\text { powerline mortality }\end{array}$ & $\begin{array}{l}\text { Only collect eggs from } \\
\text { July onwards; monitor } \\
\text { field situation }\end{array}$ & $\begin{array}{l}\text { Collect all eggs; } \\
\text { monitor field } \\
\text { situation }\end{array}$ & $\begin{array}{l}\text { Collect all eggs; } \\
\text { monitor field } \\
\text { situation }\end{array}$ & $\begin{array}{l}\text { Collect all eggs; } \\
\text { monitor field } \\
\text { situation }\end{array}$ \\
\hline 2021 & $\begin{array}{l}\text { Only collect eggs from } \\
\text { July onwards unless } \\
\text { powerline mortality is } \\
\text { high, \& then consider } \\
\text { collecting eggs earlier; } \\
\text { monitor powerline } \\
\text { mortality }\end{array}$ & $\begin{array}{l}\text { Monitor the situation } \\
\text { \& act accordingly }\end{array}$ & $\begin{array}{l}\text { Monitor the situation } \\
\text { \& act accordingly }\end{array}$ & $\begin{array}{l}\text { Monitor the situation } \\
\text { \& act accordingly }\end{array}$ & $\begin{array}{l}\text { Monitor the situation } \\
\text { \& act accordingly }\end{array}$ \\
\hline $\begin{array}{l}2022 \\
\quad \text { onwards }\end{array}$ & $\begin{array}{l}\text { Monitor the situation \& } \\
\text { act accordingly }\end{array}$ & $\begin{array}{l}\text { Monitor the situation } \\
\text { \& act accordingly }\end{array}$ & $\begin{array}{l}\text { Monitor the situation } \\
\text { \& act accordingly }\end{array}$ & $\begin{array}{l}\text { Monitor the situation } \\
\text { \& act accordingly }\end{array}$ & $\begin{array}{l}\text { Monitor the situation } \\
\text { \& act accordingly }\end{array}$ \\
\hline
\end{tabular}

per year for 5 years). In this context, identification and mitigation of practical risks associated with ex situ conservation are critical to ensure that parameters match those in the above-average or best possible scenarios. Of the two risks that we rated high (Table 2), refusal of governmental permission to collect eggs was managed by beginning to request permits before the assessment, as a precautionary measure, given the time constraints, and to allow time to resubmit or modify the application if needed. Although at the time of writing, permits have been granted, this risk was rated high during the assessment because permission had not then been granted and ex situ conservation cannot begin without it (permission to harvest and transport eggs has since been granted). We rated risks associated with harvest of eggs from the wild as high because nests will have to be found by community members, and it is impossible to eliminate the possibility they will misunderstand instructions to leave eggs in the nest until ACCB staff arrive, and instead may take eggs to their homes, in an attempt to assist the project but inadvertently causing them to spoil. We also considered rating knowledge of husbandry techniques relevant to the species as high because the Bengal florican has rarely been kept in captivity, and captive breeding has never before been attempted. Good husbandry should aim to minimize adult mortality, because sensitivity analysis showed that probability of extirpation of the captive population was most heavily affected by changes in adult mortality (Supplementary Fig. 1). In our risk assessment we noted there is considerable global expertise in ex situ management and breeding of other bustard species on which we can draw; for instance the Asian houbara Chlamydotis macqueenii is bred extensively by the International Fund for Houbara Conservation, and the little bustard and great bustard Otis tarda are bred at Centro de Cría de Aves Esteparias in Spain. We have already begun receiving technical advice from the latter, which a staff member of the Angkor Centre for the Conservation of Biodiversity visited in early 2019 and again in early 2020 to learn about captive bustard husbandry. We plan to continue to expand our advisory network and formalize it through creating an advisory panel of relevant experts.

Demographic modelling indicates there is little chance that ex situ management will produce a sufficient number of Bengal floricans to reintroduce birds within 50 years (Fig. 3). Even under the best possible scenario with egg harvest rates of 10 per year for 5 years, there are unlikely to be sufficient birds to release for $20-30$ years, by which time the species will almost certainly be extinct in the wild. Participants considered this information as they worked through the decision tree to assess biological risks associated with ex situ management (Fig. 1), but concluded that, given the relatively low risk of extirpation of a wellmanaged captive population and the very high risk of extirpation of the wild population, embarking on a programme of ex situ management was prudent (Fig. 3).

Based on the assessment of risks described above, the participants re-examined Tables $1 \& 2$, and used them to develop a plan for ex situ management of the Bengal florican (Table 3), which is summarized here, with notes on what eventuated. It was hoped that as many eggs as possible would be harvested from the unprotected population at Sankor in the 2019 breeding season (April-September), but none were found. This population is declining rapidly and is likely to be extirpated within a year because the habitat has been transformed from grassland to rice (Table 3 ). At all sites, any eggs laid during July or later will be harvested, because these probably represent late or second breeding attempts that are likely to fail because of heavy rain and rising floodwater at this time. Mortality caused by the power transmission line (completed in May 2019) that bisects the stable, protected, population at Stoung-Chikreang Bengal Florican 
Scenario 1: full range
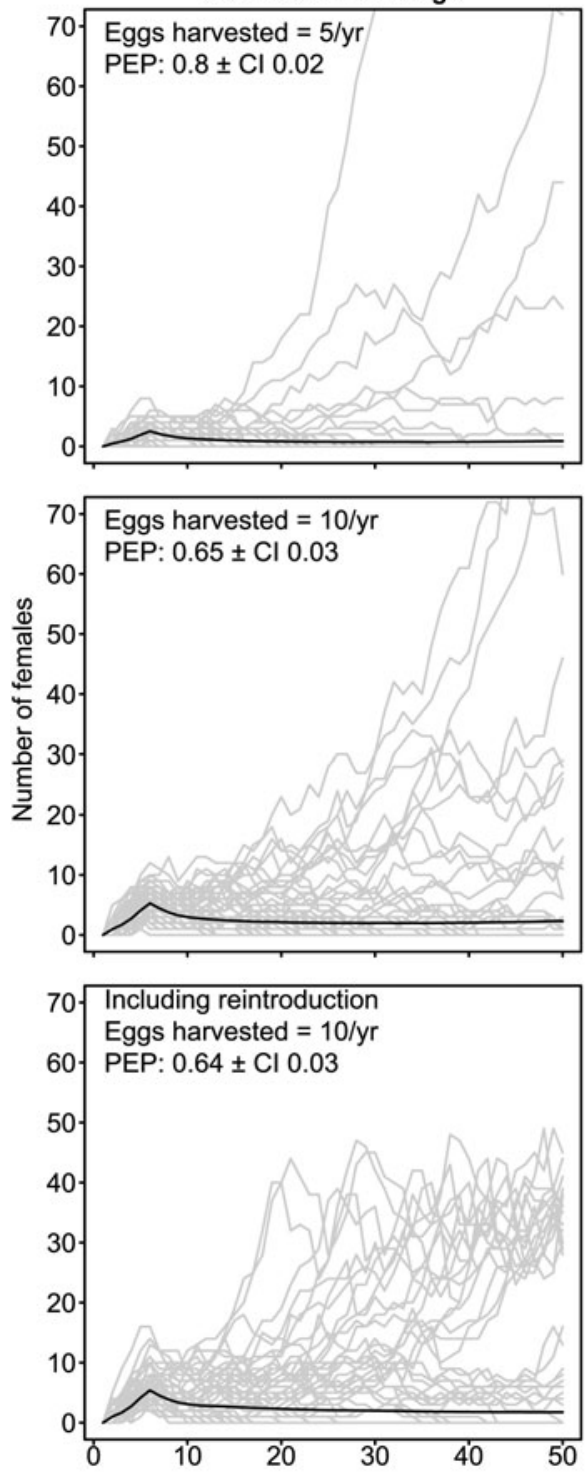

Scenario 2: above average
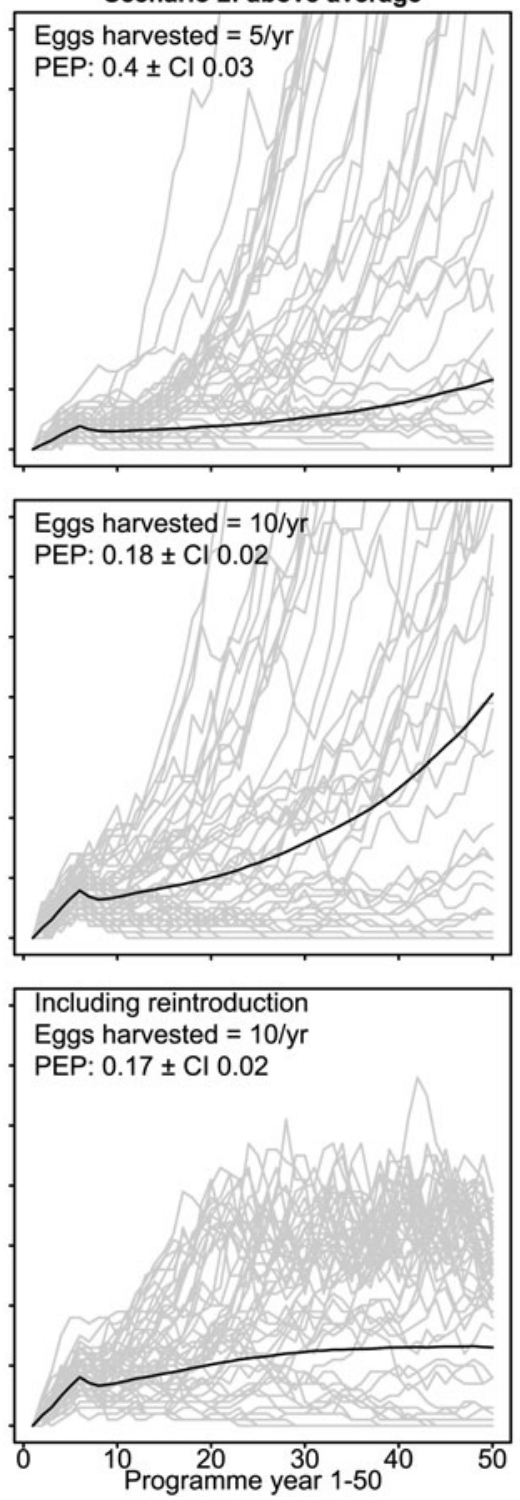

Scenario 3: best possible
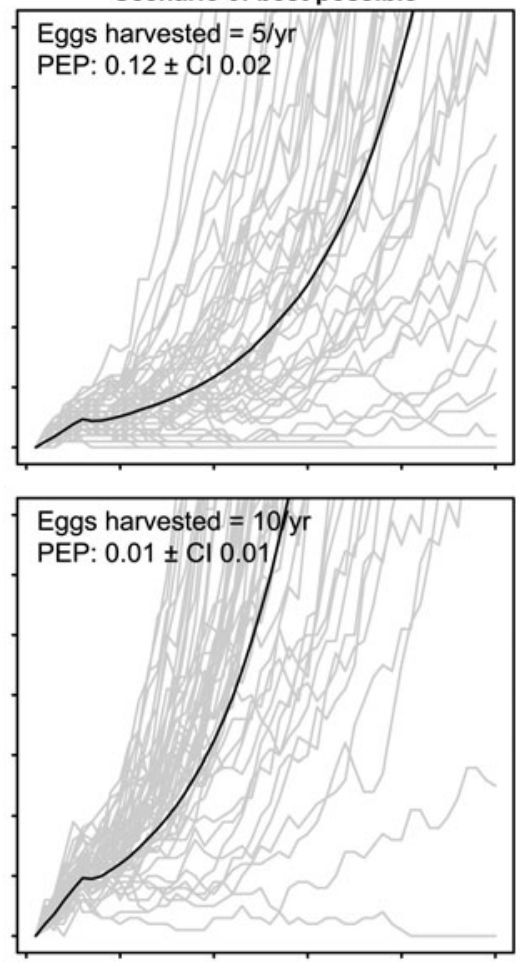

Including reintroduction Eggs harvested $=10 / \mathrm{yr}$ PEP: $0.01 \pm \mathrm{Cl} 0.01$

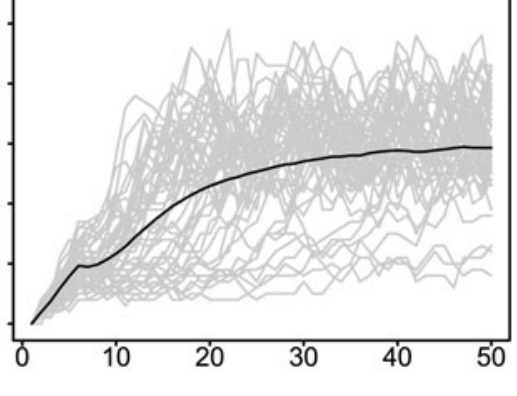

FIG. 2 Bengal florican captive demography for three scenarios of programme quality (1, full range; 2, above average; 3 , best possible) and two rates of egg harvest ( 5 or 10 eggs/year, both for 5 years), without (top and middle rows) and with (bottom row) removal of birds from the captive population for reintroduction, with probability of extinction of the ex situ programme (PEP) after 50 years. The black line shows the geometric mean of model runs.

Conservation Area was monitored throughout the 2019 and 2020 breeding seasons. Based on relatively low levels of mortality it was decided to continue restricting egg harvest to the period after July in 2019. No eggs were found in 2020, although search effort was low because of COVID-19 related restrictions on fieldwork. It was decided not to take any adults from the wild because of the high risk of mortality, which was thought likely to lead to the entire ex situ conservation programme being closed by the government. Improvements to the in situ conservation programme at the protected population in Baray Bengal Florican Conservation Area were made in early 2019; this population will be monitored intensively, and if signs of decline are detected then a decision will be made on whether to take eggs. The tiny population at Bakan will be left in the wild because efforts to harvest eggs are best directed towards locations with more individuals and there is still potential for this population to persist because funding has been secured to confer legal protection to this site. In 2019, eggs were found only at Stoung-Chikreang Bengal Florican Conservation Area, where nine eggs were collected during July-September. Five eggs hatched but two chicks subsequently died of unknown causes. Five adult Bengal floricans (three males and two females) were confiscated from hunters in 2019 (possibly owing to increased awareness) and brought to the Angkor Centre for Conservation of Biodiversity, all 

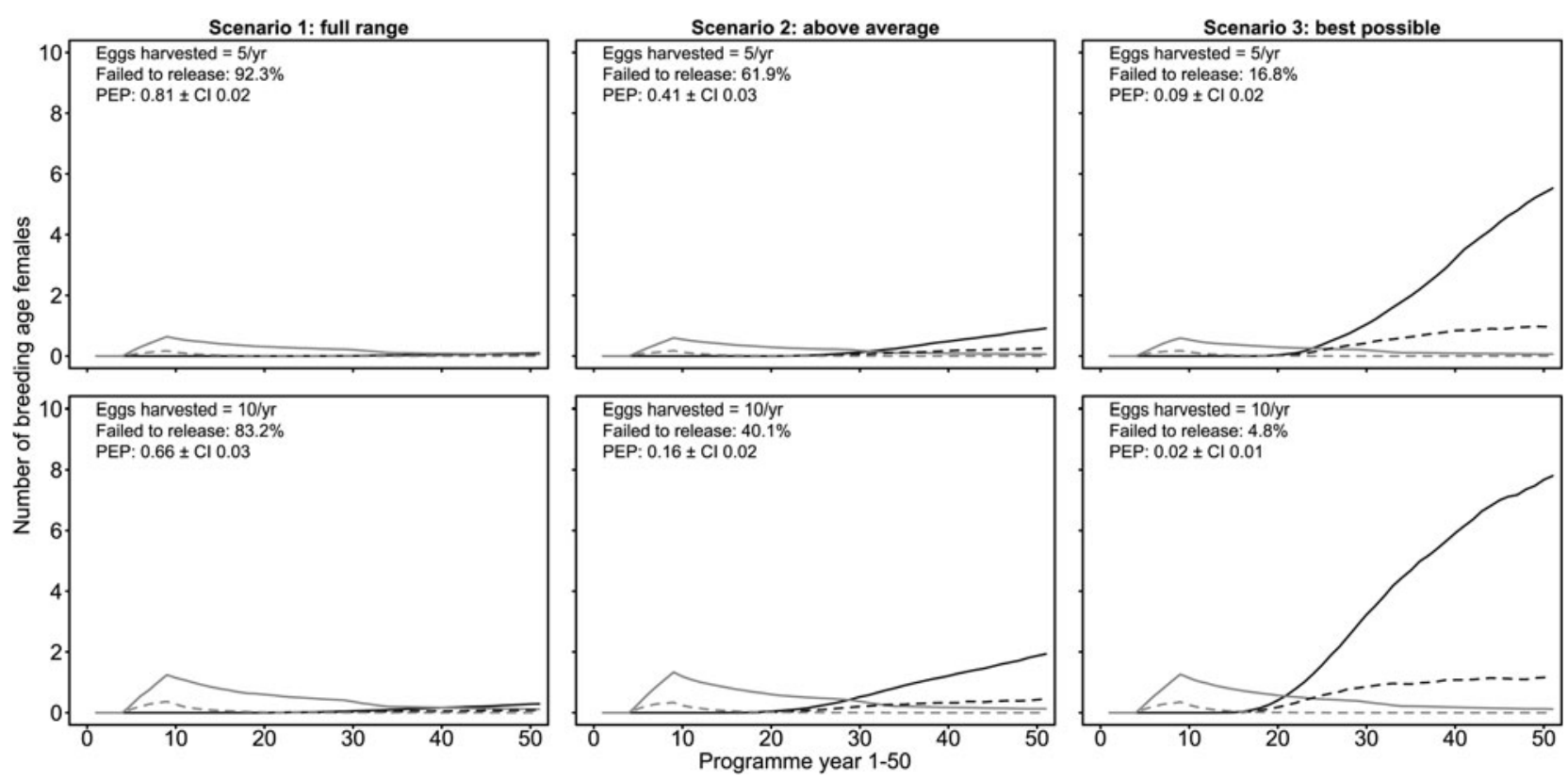

FIG. 3 Numbers of free-living adult female Bengal florican established by captive breeding and release (dark lines) or by a strategy of in situ conservation only (pale grey lines) alive in each programme year (1-50), under two scenarios of in situ conservation: current situation (solid lines), likely future situation (dashed lines). Per cent of model runs under which no birds were able to be released (failed to release) and probability of extinction of the ex situ programme (PEP) after 50 years are indicated.

survived to mid 2020 (at least) except for one female that had been missing a leg. Weekly carcass surveys recorded two Bengal florican mortalities (one male and one female) during May 2019-June 2020, so the 2019 egg collection plan was resumed in Stoung-Chikreang Bengal Florican Conservation Area in 2020. Samples will be taken from all captive individuals for molecular genotyping to determine relatedness so that we can design a captive breeding programme that maximizes fitness of offspring (Hogg et al., 2018).

\section{Discussion}

Conservation managers are increasingly forced into a situation in which they are 'held in the pressured space between extinction (as a limit on numbers and time) and the fragile wild (as a limit on intervention). Fail to intervene, and the object is lost; intervene, and the object may also be lost, although in other ways' (Reinert, 2013, p. 22). For many species, given the numbers of individuals available to be taken into captivity, and differences in selective pressure between captive and wild birds, it is inevitable that captive populations will differ from those in the wild (Frankham, 2008; Robert, 2009) even with careful genetic management of the captive flock (Williams \& Hoffman, 2009; Witzenberger \& Hochkirch, 2011). Such changes in birds include reduced brain volume of captive-bred waterfowl compared with wild birds (Guay \& Iwaniuk, 2008), reduced vigilance (Carrete \& Tella, 2015) and inappropriate behavioural responses to predators (Griffin et al., 2000).
The first questions about captive breeding are therefore philosophical: given the genetic, morphological and behavioural changes induced by captivity, conservation managers and those who support them must be satisfied that the birds that may eventually be reintroduced to the wild are approximate surrogates of the former wild populations, especially if they cannot be returned to their native range. These concepts are rarely considered explicitly in advance of ex situ conservation, but deeply-held opinions on what it means for an animal to be wild may be revealed at a stage when they can derail the process of ex situ conservation. For example, effective conservation of the California condor was delayed for several years because the prevailing ideology favoured a hands-off approach, until a change in management brought all remaining individuals into captivity and eventually reversed population declines through releases of captive-bred birds (Snyder \& Snyder, 2000). In another example, those operating captive management of the alalã (Hawaiian crow) Corvus hawaiiensis, which is extinct in the wild, have decided to teach the crows to behave in a similar way to the original forest dwelling alalã (although their habitat is different since the arrival of the feral pigs that caused them to go extinct), rather than training them to become a human commensal, as many wild populations of other crow species have done of their own volition (van Dooren, 2016).

A different approach has been taken with captive-bred Asian houbaras, which have lower fecundity, a docile temperament and differences in migration behaviour compared to wild-bred birds (Villers et al., 2010; Dolman 
et al., 2018). These changes lead to lower mortality in captivity but cause higher mortality among released captive-bred individuals compared to wild birds, as is also the case with captive-reared great bustards (Burnside et al., 2012; Dolman et al., 2018). Perhaps unsurprisingly, like most reintroduction attempts (Fischer \& Lindenmayer, 2000; Bowkett, 2009), no reintroduction of bustards has been completely successful (Dolman et al., 2015; Ashbrook et al., 2016). There is a significant chance that any reintroduction of the Bengal florican will also fail to establish a self-sustaining wild population, even if the species persists in captivity. A major impediment may be lack of habitat. If the wild population is extirpated, protection of the remaining fragments of grassland on the Tonle Sap floodplain may become harder, so habitat of the kind that is currently associated with the species may not be available for reintroduction. Although this situation is relatively common for amphibians and reptiles, which are frequently maintained in captivity until suitable conditions exist in the wild for their release (Turtle Conservation Fund, 2002; Krajick, 2006; Zippel et al., 2011), it is relatively rare in birds (BirdLife International, 2018a). In general, birds are harder to maintain in captivity than herptiles, but easier than mammals. The Guam kingfisher Todiramphus cinnamominus is so far the only bird species Extinct in the Wild never likely to be returned to its native range, because the snakes that drove it extinct cannot be eradicated, although it may be introduced to a nearby island (Laws \& Kesler, 2012). The little spotted kiwi Apteryx owenii has recently been reintroduced to predator-free sanctuaries on the New Zealand mainland; prior to this it persisted for decades only in captivity and on tiny offshore islands where it had never occurred naturally (Holzapfel et al., 2008).

For these reasons, and because ex situ management is costly and risky, it can only be justified if less intrusive alternatives are unlikely to secure species persistence (Snyder et al., 1996). By using the IUCN guidelines to assess the potential role of ex situ conservation in preventing the extinction of the Bengal florican, we were able to make a decision that comprehensively considered all of the risks, and we concluded that ex situ conservation should be attempted immediately. A similar process was used to evaluate the potential role of ex situ conservation for the South Australian subspecies of glossy black-cockatoo Calyptorhynchus lathami halmaturinus, which concluded that although technically feasible, captive management would be costly and the population would probably recover without it (Crowley et al., 1999). This proved correct: the population recovered from 195 individuals in 1995 to c. 356 individuals in 2014 without captive management (Morgan et al., 2015). In contrast, based on information available to us at the time, we concluded that we should proceed with captive management of the Bengal florican and begin egg harvest in 2019 because the wild population is likely to decline at an accelerated rate owing to new threats that are affecting the only stable population, and because the chance of establishing a captive population is relatively high if we draw on global bustard husbandry expertise to minimize adult mortality in captivity. We did not consider how best to manage the captive population to maximize genetic variation; this could have been integrated into the assessment process, but instead the breeding programme will be planned using molecular data obtained from any chicks that hatch from harvested eggs (Hogg et al., 2018).

At the time of writing we received additional information on breeding parameters of captive little bustards from Centro de Cría de Aves Esteparias. Using these data we repeated the population modelling to inform our ex situ conservation programme. Demographic modelling indicated that the chance of persistence of a captive population was better than we had predicted at the time of the workshop under all scenarios except below-average. Our estimate of probability of persistence of a captive population for 50 years under an above-average scenario increased from 60 to $79 \%$ at egg harvest rates of five per year for 5 years, and from 83 to $97 \%$ if harvest rates are 10 per year. The probability of producing sufficient individuals for release was $>75 \%$ for above-average and best possible scenarios under egg harvest rates of at least five per year for 5 years, indicating that there was a much greater chance of releasing captive-bred Bengal floricans within 50 years than we had anticipated, but failure is still possible.

Although we used the same demographic model as Dolman et al. (2015), and our model outputs are unsurprisingly similar, the conclusions that we reached are different. There are three reasons for this: (1) differences in data used to parameterize the model, (2) differences in characteristics of the counterfactual no ex situ scenario, and (3) local stakeholders led the assessment process. To parametrize the model we used data from the Bengal florican and little bustard, where it was available, in addition to the data from larger bustard species used by Dolman et al. (2015). However, this had relatively little impact on model outputs; for instance, with egg harvest rates of five per year for 5 years, Dolman et al. (2015) report probability of extinction over 50 years for the great Indian bustard under a best possible scenario of $17 \%$, compared with $11 \%$ for Bengal florican (although we report this as an $89 \%$ probability of persistence); we interpret this as an indication that if ex situ management is done well it is likely to prevent the extinction of the species. These results are compared with a counterfactual scenario for the wild population in which no egg harvest takes place. We believe that we formulated a plausible future scenario for the wild population of the Bengal florican, given trends, threats and resources available for additional in situ conservation (Mahood et al., 2019). For instance, although we believe that we know how to manage areas under rice cultivation (such as Sankor) for the Bengal florican, we do 
not have the resources to do this at the scale that is necessary within the time available, and success is at least partially dependent on factors outside our control, such as the attitudes of farmers, market forces and government policy. In contrast, the counterfactual future scenario used by Dolman et al. (2015) imagined a situation where in situ conservation was considerably more successful than has eventuated, although what was envisaged may have been possible at the time.

We aimed to use the IUCN guidelines (including model outputs and a decision tree) to support local stakeholders to make an informed, unbiased decision about ex situ management of the Bengal florican, and having made that decision, to identify risks that needed to be mitigated to maximize the chance of success. We do not want the Bengal florican to join the list of taxa that have been lost for want of a decision to evaluate ex situ conservation or initiate it in time (Woinarski et al., 2016). Demographic modelling indicates there is a reasonable chance that a captive population can be established and that in 20-30 years it should be large enough to consider reintroduction if habitat is available and threats have been mitigated. We acknowledge that such a population is likely to be small and based on a limited number of founders, so failure is possible at every step.

Our decision to attempt ex situ management of the Bengal florican was made based on a thorough evaluation of risks and resources, informed by demographic modelling. We considered both philosophical and practical issues using a decision tree. The process that we used is transparent and we hope that our decision tree will be helpful in other, similar situations. We will continue to do everything possible to prevent the loss of remaining wild populations of the Bengal florican, but we acknowledge that, if not managed properly, taking eggs and adults from the wild may accelerate declines. With hindsight, we should have considered ex situ management in 2012, when there were a number of small unprotected populations that had little chance of survival owing to financial and practical constraints on in situ conservation. Our results indicate that, with support for bustard husbandry techniques, there remains a reasonable chance of establishing a captive population. However, we anticipate that the Bengal florican may persist only in captivity for many years, and it may never be released in a situation that resembles its current wild state. We consider this is preferable to complete loss of the taxon, and captive or semi-wild individuals may serve an educational purpose. We urge conservation managers faced with rapidly declining species to evaluate comprehensively the potential role of ex situ management, rule it out whenever there is the possibility of successful conservation of wild populations, or pursue it rapidly where not.

Acknowledgements We acknowledge the ongoing support of the Royal Government of Cambodia, in particular the General
Department for Administration of Nature Conservation and Protection of the Ministry of Environment, and the Department of Wildlife and Biodiversity of the Forestry Administration, Ministry of Agriculture, Forestry and Fisheries. We thank Dolman et al. (2015) for making the $R$ code for their demographic model publicly available, and we encourage others to use it alongside the IUCN captive management guidelines (IUCN/SSC, 2014). We are grateful to two anonymous reviewers, whose comments improved this article significantly. SPM is a recipient of a Prestigious International Research Tuition Scholarship at Charles Darwin University. This research received no specific grant from any funding agency, or commercial or not-for-profit sectors.

Author contributions Study design, modelling, writing: SPM; revision, editing: $\mathrm{CH}, \mathrm{MM}, \mathrm{PF}, \mathrm{PS}, \mathrm{VS}, \mathrm{STG}$.

\section{Conflicts of interest None.}

Ethical standards This research abided by the Oryx guidelines on ethical standards.

\section{References}

Addison, P.F.E., Rumpff, L., Bau, S.S., Carey, J.M., Chee, Y.E., Jarrad, F.C. et al. (2013) Practical solutions for making models indispensable in conservation decision-making. Diversity and Distributions, 19, 490-502.

Andrew, P., Cogger, H., Driscoll, D., Flakus, S., Harlow, P., MAPLE, D. et al. (2018) Somewhat saved: a captive breeding programme for two endemic Christmas Island lizard species, now extinct in the wild. Oryx, 52, 171-174.

Ashbrook, K., Taylor, A., Jane, L., Carter, I. \& Székely, T. (2016) Impacts of survival and reproductive success on the long-term population viability of reintroduced great bustards Otis tarda in the UK. Oryx, 50, 583-592.

Balmford, A., Mace, G.M. \& Leader-Williams, N. (1996) Designing the ark: setting priorities for captive breeding. Conservation Biology, 10, 719-727.

BirdLife International (2018a) IUCN Red List for Birds. birdlife.org [accessed 17 November 2018].

BirdLife International (2018b) Species Factsheet: Houbaropsis bengalensis. datazone.birdlife.org/species/factsheet/ Bengal-Florican-Houbaropsis-bengalensi [accessed 18 May 2018].

Black, S.A., Groombridge, J.J. \& Jones, C.G. (2011) Leadership and conservation effectiveness: finding a better way to lead.

Conservation Letters, 4, 329-339.

Bowket T, A.E. (2009) Recent captive-breeding proposals and the return of the ark concept to global species conservation. Conservation Biology, 23, 773-776.

Brook, S.M., Dudley, N., Mahood, S.P., Polet, G., Williams, A.C., Duckworth, J.W. et al. (2014) Lessons learned from the loss of a flagship: the extinction of the Javan rhinoceros Rhinoceros sondaicus annamiticus from Vietnam. Biological Conservation, 174, 21-29.

BubaC, C.M., Johnson, A.C., Fox, J.A. \& Cullingham, C.I. (2019) Conservation translocations and post-release monitoring: identifying trends in failures, biases, and challenges from around the world. Biological Conservation, 238, 108239.

Burnside, R.J., Carter, I., Dawes, A., Waters, D., Lock, L., Goriup, P. \& Székely, T. (2012) The UK great bustard Otis tarda reintroduction trial: a 5-year progress report. Oryx, 46, 112-121.

Butchart, S.H.M., Walpole, M., Collen, B., van Strien, A., Scharlemann, J.P., Almond, R.E. et al. (2010) Global biodiversity: indicators of recent declines. Science, 328, 1164-1168. 
Carrete, M. \& Tella, J.L. (2015) Rapid loss of antipredatory behaviour in captive-bred birds is linked to current avian invasions. Scientific Reports, 5, 18274.

Crowley, G.M., Pedler, L.P. \& Garnett, S.T. (1999) Assessment of the Role of Captive Breeding and Translocation in the Recovery of the South Australian Subspecies of the Glossy Black-Cockatoo, Calyptorhynchus lathami halmaturinus. Birds Australia report, Hawthorn East, Australia.

Dolman, P.M., Collar, N.J. \& Burnside, R.J. (2018) Captive breeding cannot sustain migratory Asian houbara Chlamydotis macqueenii without hunting controls. Biological Conservation, 228, 357-366.

Dolman, P.M., Collar, N.J., Scotland, K.M. \& Burnside, R.J. (2015) Ark or park: the need to predict relative effectiveness of ex situ and in situ conservation before attempting captive breeding. Journal of Applied Ecology, 52, 841-850.

Fischer, J. \& Lindenmayer, D.B. (2000) An assessment of the published results of animal relocations. Biological Conservation, $96,1-11$.

Frankham, R. (2008) Genetic adaptation to captivity in species conservation programs. Molecular ecology, 17, 325-333.

Game, E.T., Kareiva, P. \& Possingham, H.P. (2013) Six common mistakes in conservation priority setting. Conservation Biology, $27,480-485$.

Gray, T.N.E., Collar, N.J., Davidson, P.J.A., Dolman, P.M., Evans, T.D., Fox, H.N. et al. (2009) Distribution, status and conservation of the Bengal florican Houbaropsis bengalensis in Cambodia. Bird Conservation International, 19, 1-14.

Gregory, R., Failing, L., Harstone, M., Long, G., McDaniels, T. \& Ohlson, D. (2012) Structured Decision Making: A Practical Guide to Environmental Management Choices. Wiley Blackwell, Oxford, UK.

Griffin, A.S., Blumstein, D.T. \& Evans, C.S. (200o) Training captive-bred or translocated animals to avoid predators. Conservation Biology, 14, 1317-1326.

Guay, P.J. \& Iwaniuk, A.N. (2008) Captive breeding reduces brain volume in waterfowl (Anseriformes). The Condor, 110, 276-284.

Harding, G., Griffiths, R.A. \& Pavajeau, L. (2016) Developments in amphibian captive breeding and reintroduction programs. Conservation Biology, 30, 340-349.

Hogg, C.J., Wright, B., Morris, K.M., Lee, A.V., Ivy, J.A., Grueber, C.E. \& Belov, K. (2018) Founder relationships and conservation management: empirical kinships reveal the effect on breeding programmes when founders are assumed to be unrelated. Animal Conservation, 22, 348-361.

Holzapfel, S., Robertson, H.A., McLennan, J.A., Sporle, W., Hackwell, K. \& Impey, M. (2008) Kiwi (Apteryx spp.) Recovery Plan 2008-2018. Department of Conservation, Wellington, New Zealand.

Ibbett, H., Lay, C., Phlai, P., Song, D., Hong, C., Mahood, S.P. \& Milner-Gulland, E.J. (2019) Conserving a globally threatened species in a semi-natural, agrarian landscape. Oryx, 53, 181-191.

Inchausti, P. \& Bretagnolle, V. (2005) Predicting short-term extinction risk for the declining little bustard (Tetrax tetrax) in intensive agricultural habitats. Biological Conservation, 122, 375-384.

IUCN (2019) The IUCN Red List of Threatened Species. Version 2019-1. iucnredlist.org [accessed 9 October 2018].

iUCN Conservation Planning Specialist Group (2019) IUCN Red List Captive Breeding Recommendations. cpsg.org/iucn-red-listcaptive-breeding-recommendations [accessed 8 March 2019].

IUCN/SSC (2013) Guidelines for Reintroductions and Other Conservation Translocations. Version 1.o. IUCN Species Survival Commission, Gland, Switzerland.

IUCN/SSC (2014) Guidelines on the Use of Ex Situ Management for Species Conservation. Version 2.o. IUCN Species Survival Commission, Gland, Switzerland.
Krajick, K. (2006) The lost world of the Kihansi toad. Science, 311, 1230-1232.

Laws, R.J. \& Kesler, D.C. (2012) A Bayesian network approach for selecting translocation sites for endangered island birds. Biological Conservation, 155, 178-185.

MaGuire, L.A. (1986) Using decision analysis to manage endangered species populations. Journal of Environmental Management, $22,345-360$.

Mahood, S.P., Hong, C., Son, V., Sum, P. \& Garnett, S.T. (2019) Catastrophic ongoing decline in Cambodia's Bengal florican Houbaropsis bengalensis population. Bird Conservation International, 30, 308-322.

Mahood, S.P., Silva, J.P., Dolman, P.M. \& Burnside, R.J. (2016) Proposed power transmission lines in Cambodia constitute a significant new threat to the largest population of the Critically Endangered Bengal florican Houbaropsis bengalensis. Oryx, $52,147-155$.

Martin, T.G., Nally, S., Burbidge, A.A., Arnall, S., Garnett, S.T., Hayward, M.W. et al. (2012) Acting fast helps avoid extinction. Conservation Letters, 5, 274-280.

McCleery, R., Hostetler, J.A. \& Oli, M.K. (2014) Better off in the wild? Evaluating a captive breeding and release program for the recovery of an endangered rodent. Biological Conservation, $169,198-205$

McGowan, P.J.K., Traylor-Holzer, K. \& Leus, K. (2017) IUCN guidelines for determining when and how ex situ management should be used in species conservation. Conservation Letters, $10,361-366$.

Morgan, D., Barth, M. \& Kinloch, M. (2015) The South Australian Subspecies of the Glossy Black-Cockatoo (Calyptorhynchus lathami halmaturinus) Strategic Plan 2015-2020. Natural Resources Kangaroo Island, Kingscote, Australia.

Packman, C.E., Gray, T.N.E., Collar, N.J., Evans, T.D., van Zalinge, R.N., Son, V. et al. (2013a) Rapid loss of Cambodia's grasslands. Conservation Biology, 27, 245-247.

Packman, C.E., Showler, D.A., Collar, N.J., Son, V., Mahood, S.P., Handschun, M. et al. (2013b) Rapid decline of the largest remaining population of Bengal Florican Houbaropsis bengalensis and recommendations for its conservation. Bird Conservation International, 24, 429-437.

Panfylova, J., Ewen, J.G. \& Armstrong, D.P. (2019) Making structured decisions for reintroduced populations in the face of uncertainty. Conservation Science and Practice, 1, e9o.

REDFORD, K.H. \& TABER, A. (200o) Writing the wrongs: developing a safe-fail culture in conservation. Conservation Biology, 14, 1567-1568.

Redford, K.H., Amato, G., Baillie, J., Beldomenico, P., Bennett, E.L., Clum, N. et al. (2011) What does it mean to successfully conserve a (vertebrate) species? BioScience, 61, 39-48.

Redford, K.H., Jensen, D.B. \& Breheny, J.J. (2012) Integrating the captive and the wild. Science, 338, 1157-1158.

Regan, H.M., Ben-Haim, Y., Langford, B., Wilson, W.G., Lundberg, P., Andelman, S.J. \& Burgman, M.A. (2005) Robust decision-making under severe uncertainty for conservation management. Ecological Applications, 15, 1471-1477.

ReINERT, H. (2013) The care of migrants: telemetry and the fragile wild. Environmental Humanities, 3, 1-24.

Robert, A. (2009) Captive breeding genetics and reintroduction success. Biological Conservation, 142, 2915-2922.

Seddon, P.J., Armstrong, D.P. \& Maloney, R.F. (2007) Developing the science of reintroduction biology. Conservation Biology, 21, 303-312.

Snyder, N. \& Snyder, H. (200o) The California Condor: A Saga of Natural History and Conservation. Academic Press, London, UK. 
Snyder, N.F.R., Derrickson, S.R., Beissinger, S.R., Wiley, J.W., Smith, T.B., Toone, W.D. \& Miller, B. (1996) Limitations of captive breeding in endangered species recovery. Conservation Biology, 10, 338-348.

SPECIES360 (2020) species36o.org [accessed 5 October 2020].

Turtle Conservation Fund (2002) A Global Action Plan for Conservation of Tortoises and Freshwater Turtles. Strategy and Funding Prospectus 2002-2007. Conservation International and Chelonian Research Foundation, Washington, DC, USA.

VanderWerf, E.A., Groombridge, J.J., Fretz, J.S. \& Swinnerton, K.J. (2006) Decision analysis to guide recovery of the po'ouli, a Critically Endangered Hawaiian honeycreeper. Biological Conservation, 129, 383-392.

van Dooren, T. (2016) Authentic crows: identity, captivity and emergent forms of life. Theory, Culture \& Society, $33,29-52$.

Villers, A., Millon, A., Jiguet, F., Lett, J.M., Attié, C., Morales, M.B. \& Bretagnolle, V. (2010) Migration of wild and captive-bred little bustards Tetrax tetrax: releasing birds from Spain threatens attempts to conserve declining French populations. Ibis, $152,254-261$.
Williams, S.E. \& Hoffman, E.A. (2009) Minimizing genetic adaptation in captive breeding programs: a review. Biological Conservation, 142, 2388-2400.

Witzenberger, K.A. \& Hochirirch, A. (2011) Ex situ conservation genetics: a review of molecular studies on the genetic consequences of captive breeding programmes for endangered animal species. Biodiversity and Conservation, 20, 1843-1861.

Woinarski, J.C.Z., Garnett, S.T., Legge, S.M. \& Lindenmayer, D.B. (2016) Conservation practice: a very preventable mammal extinction. Nature, 535, 493

Woinarski, J.C.Z., Garnett, S.T., Legge, S.M. \& Lindenmayer, D.B. (2017) The contribution of policy, law, management, research, and advocacy failings to the recent extinctions of three Australian vertebrate species. Conservation Biology, 31, 13-23.

XI, Y.M., LU, B.Z., ZHANG, Y.M. \& FUJIHARA, N. (2002) Restoration of the crested ibis, Nipponia nippon. Journal of Applied Animal Research, 22, 193-200.

Zippel, K., Johnson, K., Gagliardo, R., Gibson, R., McFadden, M., BRowne, R. et al. (2011) The amphibian ark: a global community for ex situ conservation of amphibians. Herpetological Conservation and Biology, 6, 340-352. 